\title{
soumimed
}

\section{A Study on Employee Passion in Public Sector Banks}

K. Subramoniam

Saintgits Institute of Management, Pathamuttom, Kottayam

\begin{abstract}
Employee Passion results from overall satisfaction with the organization, its policies, procedures, products, and management practices. Hard measures of Employee Passion include retention, absenteeism, tenure, and productivity. Soft measures include employee perceptions of fairness, justice, and trust. Employee Passion is a positive emotional state of mind resulting from perceptions of worthwhile work, autonomy, collaboration, growth, fairness, recognition, connectedness to colleagues, and connectedness to leader-all of which lead to standards of behavior that include discretionary effort, long-term commitment to the organization, peak performance, low turnover, and increased tenure with the organization.

The present study explores the factors which affect the Employee Passion in public sector banks. A survey was conducted among subordinate staff, award staff, and officers in five public sector banks operating in Kottayam, Kerala. The purpose of study is to understand what motivates them to continue in the job and deliver service to the satisfaction of the customers.

The conclusion of the survey was that Employee Passion in public sector banks is a concept that extends beyond the meaning of some of the present research on employee engagement. It includes, but is not limited to, satisfaction, morale, and performance. Also, Employee Passion arises from a combination of hard and soft measures that include satisfaction, engagement, motivation, and willingness to exert discretionary effort.
\end{abstract}

Keywords: employee passion, employee engagement, discretionary effort, fairness, award staff, subordinate staff

\section{Introduction}

"Find your passion! Pursue your passion to live a long and happy life! Without passion how can you be motivated to do your job?” We hear such phrases nowadays in the business world. The meaning of 'passion' holds different interpretation. For few it is the love for their work with the exclusion of-their family, friends, and social life. For some, it is all about loving what they do without the interest to do anything else. And for others it is about pursuing their goals excluding every other thing in their life.

\section{Objectives of the Study}

1. To determine what are the factors which affect employee passion in public sector banks.
2. To measure the level of employee passion based on those factors.

\section{Literature Review}

\subsection{From Engagement to Passion}

A number of research articles about workforce engagement describe it as a heightened emotional connection to a job and organization that goes beyond satisfaction (Gubman, 1998; Gubman, 2003). Such studies support the concept that employee engagement is a critical driver of organizational productivity, profitability, and customer loyalty; and conclude that an engaged, motivated, and empowered workforce is far more likely to work at optimal levels than one that is impassionate, de-motivated, and disempowered (Blanchard, 2006). 
Workforce engagement enables people to perform well, develop a strong commitment with their employers, and vouch for them when needed. Most researchers and consultants believe workforce engagement is based on a number of workplace factors, including how well people fit in their jobs, the culture and purpose of the company, leadership (top leadership values and leadership communication), immediate supervision, social relationships, total rewards, opportunities for growth, work-life balance, and the quality of life in the work place.

Engagement is more powerful than satisfaction. In the same way, is there anything more powerful than engagement? This question was asked by many researchers. They argued that engagement may not be described as the highest level of motivation people can feel and show for their work. It falls short of true passion.

Gubman, (2003) draws a distinction between engagement and passion. Engagement seems to be mostly a function of two things: what you do and where you do it. The 'what' refers to - the work you enjoy and find challenging based on your skills. The 'where' refers to-how much you like your senior managers and your work place environment like culture, senior leadership, policies, rewards, co-workers, development, etc. Research strongly suggests that the most important 'where' factor is your immediate manager (Buckingham \& Coffman, 1999); working for an appreciative person in a lively and generous environment with an interesting job that suits your skills should enable you to be fully engaged. Gubman, (2003) suggests that engagement can be expressed as a formula:

\section{Engagement $=W^{2}$ \\ Engagement $=$ What you do $\times$ Where you do it}

What is missing in this formula is the person. Passion adds this third element: 'who' you are. Are you the kind of person who can be passionate about your work in the right circumstances? Can you sustain this feeling? Can you pass this on to others? And looking at it from a company's perspective, if you are involved in recruiting, are you recruiting these kinds of people? Are you inspiring these kinds of people? So, taking the 'who' element into consideration, Gubman proposed another formula to express passion:

\section{Passion $=W^{3}$ \\ Passion $=$ What you do $\times$ Where you do it $\times$ Who you are}

This formula goes deeper than engagement: into whom you are, as well as where you work and what you do. Passion is more like love that endures for a long time.

\subsection{Definitions of Employee Passion}

The research conducted by The Ken Blanchard Companies (2007) in the Leadership-Profit Chain, determines that there are three distinct components including an affective component (that can be assessed) focused on the feelings people have about their organizational life. There is a cognitive component, which includes logical and mental conclusions about their organizational life. In addition, there is a behavioural component assessed on hard statistics such as turn-over, absenteeism, and performance. Thus, the earlier concept of Employee Passion, published in The Leadership-Profit Chain included dimensions of satisfaction, engagement, motivation, and morale.

Original Definition: Employee Passion results from the overall satisfaction with the organization, its policies, procedure, products, and management practices. Hard measures of Employee Passion include retention, absenteeism, tenure, and productivity. Soft measures include employee perceptions of fairness, justice, and trust (Blanchard, 2006).

Further, through the research in The Leadership-Profit Chain, they determined that Employee Passion is dependent on the perceptions individuals have on organizational policies and norms. The study on Employee Passion indicates certain cognitive aspects of organizational commitment, thus defining and narrowing the variables that were most influential in forming positive emotional states of mind called "Employee Passion" and emotional perceptions of how people, through these norms, process and practice to get work accomplished. This research caused us to broaden the existing definition to:

Employee Passion is the positive emotional state of mind resulting from perceptions of worthwhile work, 
autonomy, collaborations, growth, fairness, recognition, connectivity to colleagues and connectivity to the leader-all of which lead to standards of behavior that include discretionary effort, long-term commitment to the organization, peak performance, low turn-over, and increased tenure with the organization.

\section{The Scope of the Study}

Being a simple explorative study, the scope can be extended to cognitive, affective, and behavioural components of Employee Passion. Hypotheses on these components that help to find out the relationship between these components can be proposed and tested using more sophisticated statistical tools. The study can also be extended to other sectors of services and business.

\section{Limitations of the Study}

It is a simple study using minimum statistical tools which is confined to units from public sector banks only, whereas the Indian Banking System vastly consists of public sector, private sector and co-operative sector Banks as well as Foreign Banks. The locale is confined to a small area.

\section{Study Methodology}

\subsection{Sample Size}

100 (approximately $10 \%$ of the population)

\subsection{Sample Units}

Employees from State Bank of India, State Bank of Travancore, Bank of Baroda, Union Bank of India, and Canara Bank.

\subsection{Locale}

Kottayam, Kerala

\subsection{Sampling Method}

The population was stratified into officers, Award staff and Subordinate staff proportionately. Convenient sampling proportionate for each category of units in different banks was taken.

\begin{tabular}{lcc}
\hline Bank & Population (no.) & Sample size (no.) \\
\hline State Bank of India & 181 & 18 \\
State Bank of Travancore & 642 & 64 \\
Union Bank of India & 58 & 6 \\
Bank of Baroda & 47 & 5 \\
Canara Bank & 66 & 7 \\
Total & $\mathbf{9 9 4}$ & $\mathbf{1 0 0}$ \\
\hline
\end{tabular}

Thus, the sample contained three categories in the following manner:

Officers: 18

Award staff: $\quad 66$

Subordinate staff: $\quad 16$

Total: $\mathbf{1 0 0}$

\subsection{Method of Data Collection}

Primary data through questionnaire. Secondary data from controlling offices, bank's websites, and annual reports.

\subsection{Factors Considered for Measuring Employee Passion}

Based on the Ken Blanchard Companies' study, eight factors were selected for measuring the extent of Employee Passion. They are:

1. Meaningful Work: Employees perceive the organization's larger purpose through products or services produced, consider their work to be worthwhile, and are proud of their individual actions and contributions that help the organization serve its customer.

2. Collaboration:Employeesperceive an organizational environment and culture that enhances collaboration, cooperation, and encouragement between all organizational members.

3. Fairness: Employees perceive an environment where pay, benefits, resources and work loads are fair, balanced and equitable, people treat each other with respect and leaders act in an ethical manner.

4. Autonomy: Employees perceive an environment where people have the tools, training, supports, and authority to make decisions.

5. Recognition: Employees perceive an environment where they are praised, recognized, and appreciated by colleagues and their leader for their accomplishments, where they receive monetary compensation for those 
accomplishments, and where they are contributing to positive relationships with others.

6. Growth: Employees perceive an environment where people have opportunities to learn, grow professionally and develop skills that lead to advancement and career growth.

7. Connectedness with Leader: Employees perceive an environment where they trust their leader and where the leader makes an effort to form an interpersonal connection with them.

8. Connectedness with Colleagues: Employees perceive an environment where they trust their colleagues and where their colleagues make an effort to form an interpersonal connection with them.

\subsection{A Conceptual Model for Employee Passion}

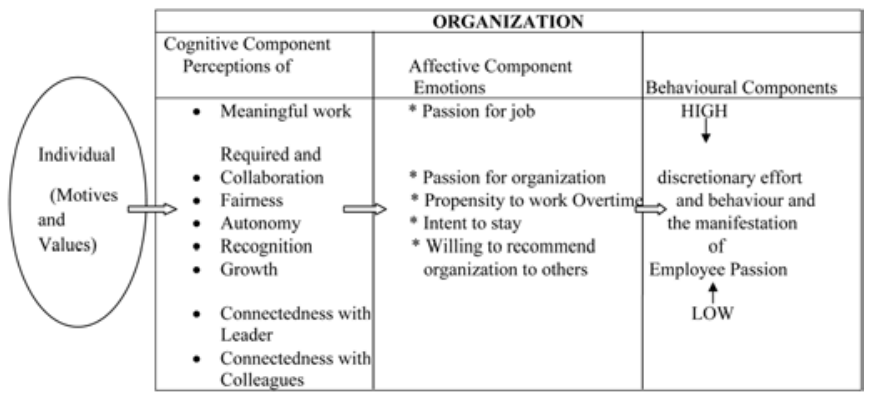

Source: Employee Passion-The New Rules of Engagement. (C2007 The Ken Blanchard Companies.

\subsection{Collection of response on each factor and interpretation}

The following questions were asked to the respondents to know their response on each factor respectively:

1. Does your Bank offer quality service to satisfy/ delight your customer and offer social circle activities for the society?

2. Does your Bank encourage sharing of ideas, interdependence and team spirit?

3. Do you feel that the benefits offered to employees and workloads are fair and balanced across the organization?

4. Do you feel that the Bank authorities trust you to do your job without interference?

5. Have you received any verbal, written or monetary recognition from your Bank for good work done?
6. Do you feel that you have enough opportunities for career development and growth?

7. Do you feel that the Manager or supervisors take a personal or professional interest on you?

8. Do your colleagues help in your work and show trust on you?

The responses are either 'yes' or 'no'. The response 'yes' was assigned a score of 1 and 'no' a score of 0 . Thus a respondent can get a maximum score of 8 and a minimum score of 0 . The score were interpreted in the following manner:

Score 0 - 2: Low Employee Passion

Score 3 - 5: Medium Employee Passion

Score 6 - 8: High Employee Passion

\subsection{Testing of Questionnaire for Validation}

The questionnaire was tested for validation among 10 non samples comprising of three categories of staff (i.e., Officers, Award staff and Subordinate staff)

\section{Results}

The factors used for measuring Employee Passion in the study are independently analyzed as below:

\subsection{Meaningful Work}

\begin{tabular}{lccrc}
\hline & Yes & Percentage & No & Percentage \\
\hline Officers & 14 & 77.78 & 4 & 22.22 \\
Award staff & 44 & 66.68 & 22 & 33.32 \\
Subordinate staff & 7 & 43.75 & 9 & 56.25 \\
Total & 65 & 65.00 & 35 & 35.00 \\
\hline
\end{tabular}

Interpretation: $65 \%$ of the respondents feel that their work is meaningful

\subsection{Collaboration}

\begin{tabular}{lccrc}
\hline & Yes & Percentage & No & Percentage \\
\hline Officers & 11 & 61.11 & 7 & 38.89 \\
Award staff & 52 & 78.79 & 14 & 21.21 \\
Subordinate staff & 9 & 56.25 & 7 & 43.75 \\
Total & $\mathbf{7 2}$ & $\mathbf{7 2 . 0 0}$ & $\mathbf{2 8}$ & $\mathbf{2 8 . 0 0}$ \\
\hline
\end{tabular}

Interpretation: $72 \%$ of the respondents believe that they get collaboration from the Bank 


\subsection{Fairness}

\begin{tabular}{lcccc}
\hline & Yes & Percentage & No & Percentage \\
\hline Officers & 16 & 88.88 & 2 & 11.22 \\
Award staff & 59 & 89.39 & 7 & 10.61 \\
Subordinate staff & 14 & 87.50 & 2 & 12.5 \\
Total & $\mathbf{8 9}$ & $\mathbf{8 9 . 0 0}$ & $\mathbf{1 1}$ & $\mathbf{1 1 . 0 0}$ \\
\hline
\end{tabular}

Interpretation: $89 \%$ of the respondents believe that their Bank treats them fairly.

\subsection{Autonomy}

\begin{tabular}{lcccc}
\hline & Yes & Percentage & No & Percentage \\
\hline Officers & 15 & 83.33 & 3 & 16.67 \\
Award staff & 32 & 48.48 & 34 & 51.58 \\
Subordinate staff & 4 & 25.00 & 12 & 75.00 \\
Total & $\mathbf{5 1}$ & $\mathbf{5 1 . 0 0}$ & $\mathbf{4 9}$ & $\mathbf{4 9 . 0 0}$ \\
\hline
\end{tabular}

Interpretation: $51 \%$ of the respondents feel that they have autonomy in their work.

\subsection{Recognition}

\begin{tabular}{lcccc}
\hline & Yes & Percentage & No & Percentage \\
\hline Officers & 16 & 88.88 & 2 & 11.12 \\
Award staff & 57 & 86.36 & 9 & 13.64 \\
Subordinate staff & 13 & 81.25 & 3 & 18.75 \\
Total & $\mathbf{8 6}$ & $\mathbf{8 6 . 0 0}$ & $\mathbf{1 4}$ & $\mathbf{1 4 . 0 0}$ \\
\hline
\end{tabular}

Interpretation: $86 \%$ of the employees feel that they are being recognized by their Banks for the good work.

\subsection{Growth}

\begin{tabular}{lccrc}
\hline & Yes & Percentage & No & Percentage \\
\hline Officers & 14 & 77.78 & 4 & 22.22 \\
Award staff & 53 & 80.30 & 13 & 19.70 \\
Subordinate staff & 7 & 43.75 & 9 & 56.25 \\
Total & $\mathbf{7 4}$ & $\mathbf{7 4 . 0 0}$ & $\mathbf{2 6}$ & $\mathbf{2 6 . 0 0}$ \\
\hline
\end{tabular}

Interpretation: $74 \%$ of the employees believe that the Banks are giving opportunities for growth in the organization.

\subsection{Connectedness with Leader}

\begin{tabular}{lccrc}
\hline & Yes & Percentage & No & Percentage \\
\hline Officers & 11 & 61.11 & 7 & 38.89 \\
Award staff & 31 & 46.97 & 35 & 53.03 \\
Subordinate staff & 7 & 43.75 & 9 & 56.25 \\
Total & $\mathbf{4 9}$ & $\mathbf{4 9 . 0 0}$ & $\mathbf{5 1}$ & $\mathbf{5 1 . 0 0}$ \\
\hline
\end{tabular}

Interpretation: Only $49 \%$ of the employees feel their connectedness to their leader.

\subsection{Connectedness to Colleagues}

\begin{tabular}{lccrc}
\hline & Yes & Percentage & No & Percentage \\
\hline Officers & 14 & 77.78 & 4 & 22.22 \\
Award staff & 54 & 81.81 & 12 & 18.91 \\
Subordinate staff & 12 & 66.66 & 4 & 33.34 \\
Total & $\mathbf{8 0}$ & $\mathbf{8 0 . 0 0}$ & $\mathbf{2 0}$ & $\mathbf{2 0 . 0 0}$ \\
\hline
\end{tabular}

Interpretation: $80 \%$ of the respondents feel that they are connected to their colleagues.

\subsection{Ranking of Success Factors}

Based on the percentage of positive responses the above eight factors are ranked below.

\begin{tabular}{llcc}
\hline SI. No. & Factor & Percentage & Rank \\
\hline 1 & Fairness & 89 & 1 \\
2 & Recognition & 86 & 2 \\
3 & Connectedness with Colleagues & 80 & 3 \\
4 & Growth & 74 & 4 \\
5 & Collaboration & 72 & 5 \\
6 & Meaningful work & 65 & 6 \\
7 & Autonomy & 51 & 7 \\
8 & Connectedness with leaders & 49 & 8 \\
\hline
\end{tabular}

\section{10 Employee Passion Score}

\begin{tabular}{lccccccc}
\hline & Officers & $\%$ & $\begin{array}{c}\text { Award } \\
\text { staff }\end{array}$ & $\begin{array}{c}\text { Subordinate } \\
\text { staff }\end{array}$ & Total \\
\hline Score : $0-2$ & Nil & 0 & 6 & 9.09 & 4 & 25.00 & 10 \\
Score : $3-5$ & 4 & 22.22 & 23 & 34.85 & 9 & 56.25 & 36 \\
Score : $6-8$ & 14 & 77.78 & 37 & 56.06 & 3 & 18.75 & 54 \\
\hline
\end{tabular}

Interpretation

54\% Employees have high Employee Passion.

36\% Employees have medium Employee Passion.

10\% Employees have low Employee Passion.

\section{Discussion}

\subsection{Overall Employee Passion Score}

The Employee Passion score reveals that majority of the employees (54\%) in the Public Sector banks has high Employee Passion.

\subsection{Employee Passion Score of Three Categories of Employees:}

Further, Officers (77.78\%) have more Employee Passion compared to Award staff (56.06\%) and Subordinate staff $(18.75 \%)$. Analysis of data reveals that Officers scored 
high in all the eight factors influencing Employee Passion. Discussion with the respondents revealed that Officers of Public Sector banks enjoys many perquisites like leased accommodation, petrol allowance, Newspaper allowance, etc and functional autonomy. Some of these perks are confined to them only and not being extended to other staff members.

\subsection{Fairness}

Majority (89\%) of respondents perceive that the pay, benefits, resources, and workload are fair and equitable. People treat each other with respect. Managers and supervisors act in an ethical manner.

\subsection{Recognition}

Majority (86\%) of employees perceive that the good work done by them is being appreciated by the Management of Banks. Banks have the system of issuing deposit mobilization certificates and appreciation letter for recovery of dues. Banks have also introduced incentive system for business development.

\subsection{Connectedness with Colleagues}

Majority (80\%) of respondents perceived that they keep solid relationship with colleagues and co-workers. They keep more personal relation with co-workers in addition to professional work relationships. People want to care about others and they want others to care about them.

\subsection{Growth}

Majority (74\%) of bank employees are of the opinion that they receive ample opportunities to learn and grow professionally and develop skills that lead to advancement in their career. Banks have a strong training system and they encourage employees to pass JAIIB and CAIIB examinations conducted by Indian Institute of Banking and Finance (IIBF) by providing additional increments for successful completion. For promotions, such qualifications are given additional weightage.

\subsection{Collaboration}

Majority (72\%) feel that there exists an organizational environment and culture that enhances collaboration, cooperation, and encouragement between all organizational members. Some banks conduct festivals for the employees and encourage them to participate in the cultural and sports events. These types of activities, annual gifts to employees, etc. help to develop a "we feeling” among the employees.

\subsection{Meaningful Work}

Majority (65\%) of the staff are finding their job meaningful. They are of the opinion that new facilities like ATMs, Net banking, Electronic Fund Transfer etc. using the power of technology is making the customer's life easy. More over, Banks are engaging in many social activities as a part of discharging their corporate social responsibilities. These factors have improved the image of Banks and Staffs among the general public. Hence majority perceive their job as worthwhile.

\subsection{Autonomy}

Only $51 \%$ of employees perceive that they have been given tools, training, supports, and authority. In Indian Banking sector Officers have more functional freedom. Hence $83.33 \%$ of officer respondents perceived that they have autonomy.

\subsection{Connectedness with Leaders}

Only $49 \%$ of respondents felt connectedness with the leader. This shows that sharing of information and rapport building by leaders in banking sector need improvement.

Based on the survey analysis, the factor that appeared to be most present in the minds of the respondents is 'fairness' followed by 'recognition'? The factor that appears to be least present is 'connectedness with leader'.

\section{Conclusion}

Employee Passion is a concept that extends beyond the meaning of the concept of employee engagement. It includes satisfaction, morale and performance, but not limited to these. Employee Passion arises from a combination of hard and soft measures that include satisfaction, engagement, motivation, and willingness to exert discretionary effort.

Bank employees in India are a privileged class and they enjoy a special position in the society. The present 
study reveals that most of them have high level of passion towards their work. Employee Passion among Bank employees is dependent on and achieved through a balance of eight critical success factors, which include:

- Fairness

- Recognition

- Connectedness with Colleagues

- Growth

- Collaboration

- Meaningful work

- Autonomy

- Connectedness with leaders

Fairness is found to be the most important factor influencing Employee Passion, followed by recognition. These two factors can be further strengthened. However, autonomy and connectedness with leaders are the factors which least influence Employee Passion which can be further studied. The banking sector is one which is closely monitored and well-regulated sector. The Supervisory Review Process suggested by Basel-II Accord is tight and employees may not be feeling functional autonomy.

But in spite of all these, Banks must provide meaningful work, autonomy (with in the ambit of regulations), access to leaders, fairness, collaboration with colleagues, recognition and opportunities for growth to the employees to enhance their passion towards work. When Employee Passion is maximized, it in turn leads to devoted customers, which results in sustainable growth, profits, and higher stock value. Finally, Banks will be benefited by improving Employee Passion.

\section{References}

Blanchard, S., Essary, V., \& Zigarmai, D. (2006). The Leadership Profit Chain. Ken Blanchard Companies, New York.

Buckingham, M., \& Coffman, C. (1999). First, Break All the Rules: What the World's Greatest Managers Do differently. Simon and Schuster, New York.

Gubman, E. (1998). The Talent Solution. McGraw-Hill, New York.

Gubman, E. (2003). The Engaging Leader, Dearhorn, Chicago.

The Ken Blanchard Companies (2007). The New Rules of Companies, New York.

\section{About the Author}

Subramoniam K. has an MBA with specialization in Finance and holds M.Phil Degree in Management. He started his career as a Probationary Officer in State Bank of Travancore (SBT) in 1985 and later worked as Branch Manager in many branches and also as Manager (Training) in Staff Learning Centre of SBT. He has also worked as General Manager and CEO of Kottayam Co-operative Urban Bank in Kottayam District of Kerala. He is presently working as Assistant Professor in Saintgits Institute of Management, Kottayam, Kerala, affiliated to M.G. University, Kottayam. He has presented papers in many national and international seminars. He is a banking trainer accredited by State Bank Academy, Gurgaon. In his career spanning 27 years, he has worked as Bank Official, CEO, trainer and academician. He can be reached at ksubramoniam2004@yahoo.com 